\title{
EL PROYECTO DE MEDIACIÓN DE LA SANTA SEDE COMO ALTERNATIVA A LA GUERRA DE SUCESIÓN ESPAÑOLA
}

\author{
DAVID MARTÍN MARCOS
}

Escuela Española de Historia y Arqueología en Roma-CSIC

\section{LA ACEPTACIÓN DEL TESTAMENTO DE CARLOS II POR LUIS XIV Y EL PANORÁMA POLÍTICO EUROPEO A PRINCIPIOS DEL SIGLO XVIII}

Cuando la noticia de la muerte de Carlos II y la sucesión favorable a uno de los hijos del Delfín llegó a París el 9 de noviembre de 1700, a Luis XIV se le presentó un dilema del que en adelante iba a depender el equilibrio de toda Europa: aceptar la voluntad del último de los Austrias españoles de que la Monarquía pasase de modo íntegro al duque de Anjou o respetar la división de los territorios españoles, según lo acordado con las potencias marítimas en el Segundo Tratado de Partición de La Haya. Si se optaba por la primera opción, el mapa europeo continuaría tal y como se había dibujado en Ryswick en 1697; si, en cambio, se prefería la segunda, el Imperio español quedaría reducido drásticamente. De ser así, el archiduque Carlos recibiría todas las posesiones de ultramar y España, salvo Guipuzcoa, que, junto con la mayoría de los territorios de Italia, iría a parar al Delfín; el Estado de Milán, por último, sería gobernado por el duque de Lorena, a cambio de que el enclave que éste poseía hasta ese momento pasase a formar parte de Francia. Puede creerse que la actitud posterior del Cristianisimo, al decantarse por la solución que aumentaba enormemente el patrimonio de su familia, provocó la guerra en Europa, pero lo cierto es que, como ha escrito Henry Kamen, el estallido del conflicto hubiese sido inevitable independientemente de la postura de Francia. Si hubiese revalidado la Partición se habría topado con la oposición de España, con el apoyo del Imperio. Además, la sucesión hubiese pasado al archiduque Carlos, y Luis XIV habría atacado al emperador para evitar que 
se hiciese con toda la herencia'. Parecía bastante claro que la paz no era más que una utopía así que lo mejor era comenzar la guerra con la corona de España en la cabeza de un Borbón. La decisión de Luis XIV no tardó en llegar. El 12 de noviembre el rey de Francia comunicó al la junta de gobierno de Madrid su intención de permitir que el duque de Anjou se convirtiese en Felipe V de España.

La rapidez con la que Luis XIV aceptó el testamento de Carlos II puede invitar a pensar que desde hacía tiempo se había tomado una decisión sobre la sucesión española. Sin embargo, la documentación aportada por Arsène Legrelle a finales del siglo XIX demostró que en París se libró un arduo debate entorno a los intereses de Francia ante el nuevo stato quo ${ }^{2}$. Las discusiones se sucedieron en la corte de Francia desde que llegaron de Madrid los primeros rumores sobre la sucesión favorable al duque de Anjou hasta que el rey cumplió con las expectativas de los españoles. De hecho, no todos los consejeros franceses eran partidarios de que un miembro de la Casa de Borbón se convirtiese en rey de España. El conde de Tallard, respaldado por Torcy, expuso las razones de esta oposición en una entrevista con Luis XIV el 2 de noviembre de 1700: resultaba ilusorio pensar que Francia lograría una paz duradera para ella y para toda Europa con la aceptación del testamento de Carlos II; el Imperio no renunciaría a sus pretensiones sin más, sin acudir a las armas; Holanda, sin las barreras de los Países Bajos, participaría en la guerra al lado del emperador e Inglaterra se sumaría a la alianza. Para calmar a los enemigos no bastaría con entregarles una o dos plazas como se había venido haciendo hasta ahora, sino que se necesitaría ceder enteros reinos, mientras que «les Espagnols eux-mêmes ne pouvaient pas s'empêcher de s'étonner que la France s'épuisât et risquât tout pour maintenir leur grandier». Ante todos esos riesgos - defendía Tallard con un discurso sorprendentemente moderno-, no valía la pena lo que ofrecía el testamento porque, por más que Luis XIV, como padre, pudiese tener ciertos deseos de conseguir reinos para sus hijos, debía defender los intereses del Estado como rey de Francia ${ }^{3}$.

Aunque parece que las anotaciones de Tallard hicieron mella en el pensamiento del monarca francés (dos días después ordenó a su embajador en Holanda que comunicase al pensionario Hensius su intención de ratificar el Tratado de Partición), la correspondencia con el marqués de Blècourt, que había sustituido a Harcourt al frente de la embajada de Francia en España en mayo de 1700, apunta hacia cierta ambigüedad. En las cartas al embajador se hace hincapié en la solidez de los acuerdos con las potencias marítimas, al tiempo que se recuerda que éstos no estaban exentos de cambios en el caso de que se optase por aceptar la oferta de los españoles.

Finalmente, cuando llegó la noticia de la muerte de Carlos II a París se decidió, después de diversas reuniones del rey con sus consejeros, aceptar el testamento. La

1. H. Kamen, España en la Europa de Luis XIV, en VVAA., Historia de España fundada por Ramón Menéndez Pidal. La Transición del siglo XVII al XVIII, tomo XXVIII, Madrid, 1997, p. 244.

2. M. A. LegriLLE, L'acceptation du Testament de Charles II roi d'Espagne par Louis XIV, Gand, 1892.

3. Ivi, pp. 6-8. 
negativa del Imperio a cualquier solución que no reconociese los derechos del archiduque Carlos sobre todos los territorios de la Monarquía española no había servido para amedrentar a los franceses.

La pomposa ceremonia oficial en la que Luis XIV presentó a Felipe V en París confirmó el paso de España y todos sus territorios a manos del Borbón. El archiđuque Carlos, salvo la dudosa garantía de ocupar el tercer puesto -tras el duque de Berry-en el derecho a la sucesión, no obtuvo nada. La mayoría de Europa se resignó ante el potencial francés y optó por entablar relaciones diplomáticas con el nuevo soberano. Inglaterra y las Provincias Unidas, los dos países que podían lamentarse del incumplimiento del Tratado de Partición, no plantearon reivindicaciones; después de todo, el testamento señalaba expresamente la separación entre España y Francia y no planteaba amenazas aparentes para los intereses angloholandeses. En Italia, al igual que en los Países Bajos, la noticia fue acogida en un primer momento con alegría; Clemente $\mathrm{XI}$, que ya empezaba a plasmar las bases de un Estado de la Iglesia con más peso en política internacional, el 6 de febrero de 1701 escribió un breve, en respuesta a una carta escrita desde Burdeos, en el que deseaba fortuna a Felipe V (Regi Catholico) al frente de la Monarquía de España

Pero, pese a las apariencias, particularmente en la Península Itálica se tuvo conciencia muy pronto de la fragilidad del nuevo equilibrio. Era un secreto a voces que el emperador Leopoldo I se preparaba abiertamente para la guerra contra la Casa de Borbón y que las tierras transalpinas podían ser el escenario de la futura contienda. Italia era desde hacía tiempo un territorio en el que el Imperio trataba de recuperar sus prerrogativas soberanas aprovechando la decadencia española; la muerte de Carlos II hacía más fácil cualquier intento en esa dirección ${ }^{5}$. En Venecia, desde antes de que se conociese la aceptación del testamento por parte de Luis XIV, el Senado aguardaba a que el Imperio solicitase permiso a la República para atravesar su territorio y desplegar sus tropas en Italia. De hecho, cuando aún no se conocía que el duque de Anjou iba a ser el nuevo rey de España, Viena -avisaba el nuncio- ya había enviado a Turín a Eugenio de Saboya y a Milán a Aníbal Visconte para tantear las posiciones del duque y el príncipe gobernador ante los nuevos acontecimientos ${ }^{6}$. Había que comenzar a ganarse el favor de los italianos antes de que Francia introdujese sus efectivos militares en la Península.

Las observaciones del nuncio Cusani ilustran la necesidad de las unidades políticas italianas de trazar una estrategia preventiva a la guerra que, con casi toda proba-

4. Copia del breve responsivo de Clemente XI a Felipe V, Roma, 6 de febrereo de 1701. ASV, (Archivio Segreto Vaticano), Fondo Bolognetti, 130, ff. 6-7. Otra copia en ivi, Ep. ad Princ. (Epistolae ad Principes), Registra, 83, ff. 63r-63v.

5. Valga como ejemplo el manifiesto «Dilatar l'Impero in Italia» del conde Braÿner, escrito entre los años 1693 y 1694, que ha estudiado E. BARTOLI, La Guerra di Successione spagnola nell' 'falia settentrionale: il ducato di Guastalla e Mantova tra conflitto e soppressioni, «Cheiron», 39-40, 2004, pp. 159-221.

6. Correo del nuncio Cusani al cardenal Paulucci. Venecia, 27 de noviembre de 1700. ASV, Segr. Stato (Segreteria di Stato), Venezia, 148, ff. 572-573. 
bilidad, iba a desarrollarse en su territorio; el conflicto, aunque quedase restringido a los ataques de Austria a las Dos Coronas, les afectaba directamente por la coincidencia de intereses de los dos contendientes en Italia. Más adelante, ya fuera por algunos errores tácticos de Luis XIV o por el deseo de las potencias marítimas de hacer frente al creciente poder francés y defender sus intereses comerciales en el Mediterráneo, el emperador obtuvo el apoyo de Inglaterra y Holanda, primero, y de Saboya y Portugal, después. España y Francia quedaron prácticamente aisladas en un conflicto que afectaba a casi toda Europa y que habría de prolongarse durante años.

\section{LA ESTRATEGIA DE CLEMENTE XI ANTE LA GUERRA: HACIA LA MEDIACIÓN PONTIFICIA}

Según una polémica relación del año 1702, presentada al Senado de Venecia por Nicolo Erizzo al término de su embajada en Roma, Clemente XI, «volendo corrispondere all 'intentione del sacro Collegio, studiò subito d'imprimere una grande opinione del suo vigore, per togliere, ma non per restituire agli altri le reciproche usurpationi»? ${ }^{7}$. Más allá de los juicios morales del súbdito de la Serenísima, no muy objetivos al acabar su misión diplomática de forma drástica y accidentada, es cierto que la coincidencia entre el programa zelante y el programa político de Albani se constató inmediatamente después de que fuese elegido pontífice. Los primeros pasos del nuevo papa, marcados por una interpretación rígida de la inmunidad eclesiástica, la defensa del patrimonio dogmático post-tridentino o la recuperación del papel protagonista del Papado en las relaciones internacionales ${ }^{8}$, se orientaron hacia el viejo anhelo de la curia romana de un Estado de la Iglesia fuerte en Italia (hasta el hipotético punto de alcanzar un poder hegemónico) y mediador en las disputas entre las potencias católicas.

El cercano horizonte de la guerra en el Continente no suponía sólo riesgos para Italia sino que se presentaba como un importante reto ante las ambiciosas pretensiones del Papado. Además del ideal zelante, estaban en juego conceptos muy concretos. Nápoles, como teórico feudo pontificio, fue, en este sentido, el arma a utilizar por Clemente XI en la mediación ante la España de Felipe V (junto con la Francia de Luis XIV) y el Imperio de Leopoldo I, las dos entidades políticas interesadas en ese territorio. Poco después de la muerte de Carlos II, pero antes de que se supiese de la aceptación de su testamento por Luis XIV, el nuncio pontificio monseñor Acquaviva ya había expuesto abiertamente en Madrid los derechos de la Santa Sede sobre Nápoles y Sicilia mediante una nota pública'. El gesto, pese a que fue protagonizado de mane-

7. Relazione, 17024 novembre, del nob. Uomo Nicolò Erizzo tornato da ambasciatore a Roma sotto il pontificato d'Innocenzo XII, e di Clemente XI, en B. CECCHETTI, La Repubblica di Venezia e la Corte di Roma, nei rapporti della religione, II, Venecia, 1874, p. 328.

8. S. TABACCHI, L'impossibile neutralità. Il papato, Roma e lo Stato della Chiesa durante la Guerra di Successione spagnola, «Cheiron», 39-40, 2004, p. 225.

9. «Perteneciendo a la Santa Sede Apostolica el Dominio directo sobre los Reynos de Napoles y Sicilia; y por la muerte sucedida de la gloriosa memoria del Rey Carlos Segundo sin legitimos descendientes, debolviendose a la misma Santa Sede Apostolica el total Dominio de los dichos Reynos: Yo Don Francisco, 
ra independiente por el nuncio, como él mismo reconoció poco después ${ }^{10}$, dejaba ya entrever cual era el plan a seguir por Roma en lo sucesivo. Partiendo del control teórico de ese territorio (el efectivo seguía obviamente en manos de España), Roma podja reforzar su candidatura para desempeñar el papel de primo inter pares en las disputas entre príncipes católicos. De hecho, el escrito de Acquaviva se encuadraba dentro las numerosas relaciones que la curia romana difundió aquellos años por Europa para revitalizar y recordar los privilegios y la soberanía que ejercía en el sur de Italia a los soberanos interesados en recibir la investidura de ese territorio. Esas composiciones eran, en la mayoría de los casos, disertaciones de carácter histórico-jurídico con las que se pretendía remontar el derecho de la Santa Sede sobre Nápoles y Sicilia a principios del siglo IX, cuando el emperador Ludovico, hijo de Carlo Magno, había procedido a la donación de ambos reinos al papa Pascual I"I.

Así, Clemente XI, sabedor de que una eventual guerra podría afectar de lleno a Italia y, quizás, también a los Estados Pontificios, envió breves a Leopoldo I, a su hijo José y a Luis XIV el 28 de diciembre de 1700 en los que instaba a Francia y, sobre todo, al Imperio a optar por el diálogo para solucionar sus diferencias y evitar la guerra en el Continente ${ }^{12}$. Su proyecto fue acogido favorablemente por la corte de París, que, con el control indirecto de las posesiones españolas en Europa a través de Felipe V, partía desde una posición ciertamente ventajosa. Francia podía sugerir a Clemente XI una alianza de todos los príncipes italianos con las Dos Coronas, en el caso de que sus insinuaciones no lograsen apartar a Leopoldo I de las armas. El nuncio Gualtieri, después de presentar el breve a Luis XIV y a Torcy, transmitió además a Roma:

«le sicurezze [del rey de Francia] di non voler intentare cosa alcuna in Italia, la quale potesse pregiudicare in minima parte alla di lei libertà, anzi di voler contribuire con tutte le forze al mantenimento di essa, all 'indipendenza de' suoi Prencipi, et alla conservazione dell'armonia in cui le cose presente si trovano»' ${ }^{13}$.

arzobispo de Larissa Nuncio Apostolico en los Reynos de España, como ministro rapresentante de la Santa Sede Apostolica, en la mexor forma que puede y devo protesta de todas, y qualquier razon que le competen y pueden competir en coiunctura y por causa de la referida muerte: De manera que ninguno pueda decir se aya adquirido o ser por adquirir algun derecho o razon sobre dichos Reynos o alguno de ellos, en todo o en parte debaxo de pretexto de qualquier disposición, o qualquier otro titulo; sino en caso que la misma Santa Sede Apostolica o por ella el Summo Pontifice quiera darle, y con effecto le dè y conceda dicho derecho y razon, mediante la legitima Investitura, asi lo digo y protesto. Archiepescus Larissenem Nunzius Apostolicus»y. Nota pública del nuncio Acquaviva, Madrid, 8 de noviembre de 1700, ASV, Segreteria di Stato (Segr. Stato, Spagna), 182, ff. 453-454.

10. $/ v i$, ff. 477-479.

11. Se ha tomado como ejemplo una copia de una relación titulada Dritto della Sede Apostolica sopra il Regno di Napoli conservada en BNALC (Biblioteca Nazionale dell'Accademia dei Lincei e Corsiniana), Cors. (Manoscritti Corsiniani), 299, ff. 112-138.

12. Respectivamente en ASV, Ep. ad Princ. Registra, 83, ff. 17r-18r; ivi, 18r-19r; e ivi, 19v-20v.

13. Correo del nuncio Gualtieri al cardenal Paulucci. París, 15 de enero de 1701. ASV, Segr. Stato, Francia, 201, ff. 69-72. 
El plan de Clemente XI no gozó del mismo recibimiento en Viena. Al poco de la presentación de los breves al emperador y al Rey de Romanos (6 de enero de 1701), el conde de Harrach hizo saber al nuncio Davia que, en su opinión, la propuesta de la Santa Sede resultaría difícil de aceptar en el consejo que la debatiría en breve. Por más que el nuncio defendiese que cualquier mal era menor que la guerra, la desventajosa situación de los austriacos frente a los franceses hacía inviable que se optase por la supresión de los preparativos del conflicto. A la larga, la pasividad favorecería el pacífico éxito de Francia y reduciría las posibilidades de una victoria de Austria, que quedaría aislada $^{14}$. De hecho, tan sólo una semana antes, Leopoldo I había escrito a Clemente XI una significativa carta en la que se exponían los derechos del Imperio a la Corona de España y, consecuentemente, a la investidura del reino de Nápoles ${ }^{15}$. En la esperada reunión de Leopoldo I y su hijo José con los consejeros conde de Vallenstein, conde de Mansfeld, príncipe de Salm, príncipe de Liechtenstein, conde de Caunitz, conde de Buccelleni y conde de Harrach, aunque se confirmaron las impresiones de este último, se aprobó una posibilidad que dejaba algún resquicio para lograr la paz. Leopoldo I envió su respuesta a Clemente XI el 22 de enero de $1701^{16}$. El Imperio, según refería el nuncio Davia a la Secretaría de Estado cuatro días después ${ }^{17}$, aceptaría la mediación si las Dos Coronas y la Santa Sede aceptaban una serie de condiciones: Francia debería comprometerse a no enviar tropas en Italia o, en caso de que ya las hubiese mandado, a retirarlas; España, tendría que aceptar que los feudos de la Iglesia y del Imperio, de los que en teoría no tenía derecho a hacer disposiciones Carlos II, se mantuviesen en «sequestro neutrale» bajo la regencia de poderes imparciales (Nápoles y Sicilia permanecerían bajo el control de Clemente XI, mientras que el Estado de Milán y Flandes, pese a pertenecer a la Casa de Austria, como se decía en Viena, pasarían a ser gobernados por un príncipe italiano y otro aceptado por las dos partes, respectivamente); y Roma no sólo se comprometería a no participar en ligas con los Borbones sino que atacaría y denunciaría a aquellos estados que optasen por tales fórmulas en Italia.

Las posibilidades de que la contraoferta austriaca prosperase eran bastante reducidas dadas sus duras exigencias. Quizás por ello, los imperiales, conscientes de lo difícil que sería que sus palabras llegasen a buen puerto, al tiempo que negociaban con la Santa Sede, habían comenzado a situar sus tropas en zonas próximas a la Península

14. Correo del mincio Davia al cardenal Paulucci. Viena, 15 de enero de 1701. ASV, Segr. Stato, Germania, 238, ff. 32-34.

15. Leopoldo l a Clemente XI. Viena, 29 de diciembre de 1701. ASV, Fondo Albani, 206, ff: 30-32.

16. Leopoldo I a Clemente XI, ASV, Segr. Stato, Principi, 131, f. 175.

17. Esta carta es mucho más ilustrativa y rica de detalles que el documento firmado por el emperador; recoge de forma pormenorizada las pretensiones del Imperio según una entrevista del nuncio con el canciller conde de Caunitz. Pese a la disposición al diálogo se considera que una «parlata grave di Nostro Signore a cotesto Ambasciatore Cattolico, anche senza positivo impegno varrebbe piu di qualsi voglia spedizione espressa a Madrid per portare quella regenza a dar oreccho a temperamenti per intavolar poi la mediazione» ASV, Segr. Stato, Germania, 238, ff. 69-73. 
Italiana. El 29 de enero se avisaba desde la nunciatura de Viena de que los imperiales habían trasladado tres regimientos de infantería a Stiria y uno de artillería al Tirol ${ }^{18}$. Por si fuera poco, los agentes borbónicos en Italia parecían más pendientes de ganarse el favor de los pequeños príncipes italianos y distribuir sus tropas en zonas al norte del Po, para asegurarse una buena defensa del Estado de Milán, que de la via pacífica basada en el diálogo propuesta por la diplomacia pontificia ante un futuro conflicto armado ${ }^{19}$.

El pesimismo que Leopoldo I demostraba sobre el éxito de su plan era compartido por Clemente XI. En Roma, pese a que las pretensiones del Imperio eran enormemente beneficiosas para los intereses pontificios en Italia, se creía que la postura del Imperio era excesivamente extrema y dejaba escasos márgenes de maniobra para que las negociaciones pudiesen prosperar. La posibilidad real de una invasión de Italia por los ejércitos imperiales había sido la razón por la que ya a finales de enero de 1701 , Clemente XI había mandado llamar a los cardenales Astalli, D'Adda y Aste, respectivos legados de Ferrara, Bolonia y Urbino, para analizar, junto con Paulucci, el sistema defensivo de las fronteras del norte del Estado de la Iglesia y el potencial bélico pontificio ${ }^{20}$. La Santa Sede era consciente de que el proyecto austriaco provocaría una fuerte oposición de las Dos Coronas y decidió adelantar sus movimientos con el fin de controlar esas reacciones. E1 6 de febrero Paulucci ordenó a Acquaviva, el nuncio en Madrid, que tratase de convencer a la corte española de que las condiciones del Imperio, por más que «ardue e scabrose», se encuadraban dentro de los normales preliminares para empezar a negociar ${ }^{21}$. El día 14 de ese mismo mes instó al representante pontificio en Viena a que tratase de convencer a Leopoldo I para que introdujese algunas modificaciones en su discurso capaces de frenar un previsible descontento hispano-francés. El encuentro en audiencia privada de Davia con el emperador, por más que sirviese para arrancar la promesa austriaca de una reflexión más profunda de la difícil situación, se demostró yermo ante la determinación de esa corte. El propio nuncio admitía que,

«havendo la Maestà sua fatt'i primi passi per la mediazione e il Trattato, sperava migliore corrispondenza nell'altro partito, onde non poteva senza una somma sconsolazione sentire di venir richiesto per nuove dichiarazioni in tempo che gli altri tenevansi su la semplice negativa $\rangle^{22}$.

18. Carta del nuncio Davia al cardenal Paulucci, ivi, ff. 83-84.

19. Ya en enero el duque de Saboya había acordado con el embajador de Francia en Turín el paso de tropas francesas por el Piemonte hacia el Estado de Milán. Carta del nuncio Sforza al cardenal Paulucci, Turín, 20 de enero de 1701. ASV, Segr. Stato, Savoia, 125, f. 40; en relación a las misiones diplomáticas, valga como ejemplo la del cardenal d'Estrées en Venecia para ganarse el favor del Senado de la Serenísima y firmar una alianza contra el Imperio. Cfr. Carta del nuncio Cusani al cardenal Panlucci. Venecia, 26 de febrero de 1701. ASV, Segr. Stato, Venezia, 149, f. 156.

20. Avvisi Marescotti. Roma, 29 de enero de 1701. BNCVE (Biblioteca Nazionale Centrale Vittorio Emanuele), Vitt. Em. (Fondo Vittorio Emanuele), 790, f. 12r.

21. ASV, Segr. Stato, Spagna, 359, ff. 17r-18v.

22. Carta del nuncio Davia al cardenal Paulucci. Viena, 26 de febrero de 1701 . ASV, Segr: Stato, Germania, 238, ff. 143-145. 
Cuando en París y Madrid se tuvieron noticias de la propuesta defendida por los austriacos empezó a consumarse el fracaso del diálogo promovido por la curia romana. Los franceses, firmemente contrarios a que terceros (siempre y cuando no fuesen ellos) se ocupasen de Flandes, Nápoles y Milán, optaron por una «negativa assoluta d'ogni accomodamento $\rangle^{23}$; los españoles, por su parte, rechazaron el proyecto al considerar que implicaba dudas manifiestas del pontífice sobre los derechos sucesorios del duque de Anjou ${ }^{24}$. La oposición a una solución pacífica complicaba aún más la tranquilidad de Italia y hacía que la llegada de las tropas imperiales a la Península estuviese cada vez más próxima. El 3 de marzo Clemente XI escribió un nuevo breve al emperador en el que se hacía un desesperado apelo para que el ejército del Imperio se abstuviese de entrar en Italia. La petición de un pontífice cada vez con menos argumentos se justificaba, de manera poco convincente, en una posible propagación de un brote de peste surgido en las costas de Croacia al tener que pasar las tropas austriacas por la República de Venecia en su camino hacia la Península ${ }^{25}$. Pero al emperador «le tenian perplejo las instancias del pontífice y de los principes de Italia [...] que proponian que la guerra del estado de Milán no era justa $\rangle^{26}$. Su respuesta a las elucubraciones papales fue tajante: no sólo las razones de la Casa de Austria para ocupar el trono de España, pese el supuesto testamento de Carlos II, eran más importantes que las peticiones de Roma sino que además la guerra e incluso la peste eran dos fenómenos que no podían ser atribuidos al emperador sino a Luis XIV. Francia después de la Paz de Ryswick no había hecho sino perturbar la tranquilidad de Europa promoviendo los tratados de partición de la Monarquía española ${ }^{27}$.

Tampoco las gestiones de los nuncios pontificios en Francia y Austria corrieron mejor suerte. Gualtieri, en una entrevista en París con el conde de Sizendorff, el embajador austriaco, lo único que sacó en claro del discurso de su interlocutor fue que el Imperio entraría en negociaciones con Francia sólo si se le cedían algunos estados de la Monarquía hispánica, una oferta intolerable a ojos de los franceses ${ }^{28}$. Davia, de una serie de conversaciones con Caunitz y Harrach en Viena, obtuvo únicamente la confirmación de que el Imperio enviaría sus tropas a la Península italiana para defender los derechos de la Casa de Austria, pues Leopoldo I, por más que admiraba cómo los ita-

23. Carta del muncio Gualtieri al cardenal Paulucci. Paris, 21 de febrero de 1701. ASV, Segr. Stato, Francia, 201 , ff. $260-262$.

24. Carta del nuncio Acquaviva al cardenal Paulucci. Madrid, 3 de marzo de 1701. ASV, Segr: Stato, Spagna, 184, ff. 61-62.

25. Biblioteca Apostolica Vaticana (BAV), Vaticani Latini (Vat. Lat.), 10738, ff. 135-136.

26. F. De CASTellvi, Narraciones históricas, vol. I, Madrid, 1998, p. 202.

27. BAV, Vat. Lat., 10738, ff. 137-138.

28. Posteriormente el nuncio se entrevistó con Torcy, a quien hizo saber el contenido de la conversación mantenida con Sizendoff con la esperanza de que Francia aceptase negociar con el Imperio. El ministro francés, pese a que en un primer momento rechazó cualquie forma de diálogo, le prometió exponer el tema a Luis XIV. A pesar de la buena disposición de Torcy, Gualtieri reconocía a Paulucci su falta de esperanzas de que se llegase a algún acuerdo. Cfr. Carta del nuncio Gualtieri al cardenal Paulucci. París, 9 de marzo de 1701. ASV, Segr. Stato, Francia, 201, ff. 391r-392v. 
lianos promovían la paz, «doveva però provedere a' pregiudizii della propria Casa troppo dannificata dal Testamento del Re di Spagna [...] e dalla persistenza de' Francesi in rigettare qualsivoglia proposizione d'accordo che porti seco un minimo sospetto di separazione di quella monarchia» ${ }^{29}$. El Imperio, que durante los últimos años del reinado de Carlos II había rechazado cualquier intento de partición de las posesiones del último de los Austrias españoles, exigía a Luis XIV, sólo medio año después de la subida de Felipe $\mathrm{V}$ al trono de España, la división de los territorios hispánicos bajo la amenaza de las armas. Quizás Francia hubiese optado por aceptar algunos acuerdos pero era prácticamente imposible que los españoles permitiesen la fragmentación de su Imperio. Si uno de los hijos del Delfín se había hecho con la corona de España se debía precisamente a que la Casa de Borbón era considerada en Madrid el único poder capaz de garantizar la unidad de la Monarquía frente a los ataques de toda Europa.

La firmeza del emperador en su decisión de apostar por la guerra en Italia fue supuestamente el motivo por el que Ferdinando Carlo Gonzaga, el último de los duques de Mantua, se decidió a sellar un acuerdo secreto con las Dos Coronas. Se estipuló que las tropas hispano-francesas pasasen a ocupar el presidio de la ciudad como medida de protección frente a eventuales ataques del ejército imperial. La buena disposición de Mantua hacia los franceses no era fruto de la casualidad. Mientras que el Imperio había sido el artífice de que Ferdinando Carlo perdiese el control del ducado de Guastalla, en favor de su cuñado Vincenzo Gonzaga, en abril de 1699, Francia no sólo se había mostrado muy próxima a este estado tras Ryswick sino que un año antes había decidido enviar a un representante a la corte ducal, en calidad de embajador del Cristianísimo. y poner fin a un hiato que duraba ya cinco años ${ }^{30}$. A pesar de que el duque de Mantua tenía en mejor consideración a la Casa de Borbón, el paso de este territorio independiente, de singular importancia estratégica para el control del norte de la Península, a la órbita hispano-francesa se debió no tanto al compromiso de defenderlo de los austriacos como a la entrega de 12.000 doppie a su titular ${ }^{31}$. Las continuas contrapropuestas hechas desde la curia romana al duque de Mantua, del que desde hacía tiempo se sospechaba cierta parcialidad, para que en la plaza se formase un presidio pontificio ${ }^{32}$,

29. Carta del nuncio Davia al cardenal Paulucci. 12 de marzo de 1701. ASV, Segr. Stato, Germania, 238, ff. $177-180$.

30. Cfr. F. FANTINI D'ONofrio, Le fonti e la Storia. La Guerra di Successione spagnola a Mantova attraverso la corrispondenza ai Gonzaga da Mantova e Paesi (1701-1708), en C. M. BELFANTI, F. FANTINI D'ONOFRIO, D. FERRARI, Guerre, stati e città. Mantova e l'Italia padana dal secolo XIII al XIX, Mantua, 1988 , p. 429.

31. F. POMETTI, op. cit, XXI, p. 339, eleva la suma a 30.000 doppie. Una de las numerosas copias del acuerdo entre el ducado de Mantua y las Dos Coronas se encuentra en un correo del nuncio Cusani a la Secretaría de Estado. Venecia, 5 de marzo de 1701. ASV, Segr. Stato, Venezia, 146, ff. 172-178. Parece ser que el tratado fue formalizado entre el 22 y el 24 de febrero de 1701. Cfr. F. FANTINI D'ONOFRIO, op. cit., p. 429.

32. Ya a principios de febrero de 1701 en una Congregación de Estado en Roma, a la que asistieron los cardenales Marescotti, Sacripante, Paulucci, Spinola S. Cesareo, Spada y Tanara, se había àcordado poner a los Estados Pontificios en situación de alerta e iniciar una serie de tratativas con Venecia con el fin de poder 
y mantener así un grado de neutralidad más evidente frente a los perjuicios inherentes a la presencia de ejércitos extranjeros en Italia, fueron infructuosas. El 5 de abril, después de una supuesta acción de asalto, en la que se intentó disimular los acuerdos previos y preservar el discutido honor del duque, las tropas borbónicas hicieron su ingreso en la ciudad ${ }^{33}$.

Un correo extraordinario de Ferdinando Carlo Gonzaga a Clemente XI dio cuenta del episodio exagerando notablemente las presiones de los hispano-franceses. Las negociaciones del pontífice con el marqués de Berreti, un agente que poco antes había sido enviado por el duque a Roma con el ficticio encargo de obtener del papa el envio a Mantua de tropas papalinas procedentes de Bolonia y Ferrara, se convirtieron en papel mojado $^{34}$. Era evidente que el objetivo de la misión del agente había sido únicamente encubrir las negociaciones con los hispano-franceses. El cardenal Paulucci reconoció entonces que la mediación del papado en las disputas entre Austrias y Borbones no había dado «niuna apparenza di frutto», aunque se mostró convencido de la necesidad de seguir trabajando en esa dirección ${ }^{35}$. La obstinación del secretario de Estado por seguir manteniendo vigente el papel de átbitro de la Santa Sede entre Austrias y Borbones pronto encontró un obstáculo insalvable. Cuando en Viena se tuvo noticia de la ocupación hispano-francesa del presidio de Mantua, Leopoldo I hizo público un decreto (que, más adelante, fue difundido por sus soldados en las proximidades de la ciudad y otras localidades cercanas) por el que los bienes feudales de Francisco Ferdinando y sus consejeros se consideraban simplemente «caduchi ${ }^{36}$. En la corte no sólo no se creyó la versión del duque, según la cual el príncipe de Vaudemont y el conde de Tessè le habían forzado para que les entregase la plaza, y se apuntó acertadamente hacia la hipótesis del tratado sino que además se dispuso que dos regimientos de húsares acompañasen al ejército en su cada vez más próxima marcha hacia Italia para castigar al Estado de Mantua ${ }^{37}$. Pocos días antes, el conde de Castelbarco, el repre-

establecer un presidio pontificio en Mantua. Cfr. Despacho del embajador veneciano en Roma Niccolo Erizzo. 12 de febrero de 1701, F. NICOLINI, op. cit., vol. I, p. 361; Clemente XI, siguiendo esa misma línea, escribió varios breves al duque de Mantua de febrero a abril de ese año. Cfr. ASV, Ep ad Princ., Registra, 83, ff. 75r-76r; ivi, ff. 96r-96v.

33. Sobre la evolución del ducado de Mantua durante los primeros años del siglo XVIII véase el artículo de D. FRIGo, Impero, diritto feudale e «ragion di Stato»: la fine del ducato di Mantova (1701-1708), «Cheiron», 21, 1994, pp. 58-84.

34. El 4 de abril de 1701 Berretti había conseguido la concesión del presidio pontificio (cfr. F. FANTINI D'ONOFRIO, op. cit. p. 430), pero se anuló tras conocerse la noticia de la entrada hispano-francesa en la ciudad, cfr. Carta del cardenal Paulucci al nuncio Acquaviva. Roma, 17 de abril de 1701. ASV, Arch. Nunz, Madrid, 47, ff. 105 y ss.

35. Ibídem.

36. Decreto de Leopoldo I. Luxemburgo, 20 de mayo de 1701. ASV, Segr. Stato, Venezia, 149, f. 530.

37. Carta del nuncio Davia al cardenal Paulucci. Viena, 23 de abril de 1701. ASV, Segr. Stato, Vienna, 238, ff. $295-296$ 
sentante imperial en la corte ducal, había recibido una orden para que abandonase la ciudad sin despedirse de Ferdinando Carlo ${ }^{38}$.

A partir de entonces, Viena dejó de considerar las razones de la Santa Sede sobre la mediación y se dedicó exclusivamente a organizar sus preparativos militares para la futura empresa de Italia. Después de los pasos dados por las Dos Coronas al sur de los Alpes, tratar de convencer a Leopoldo I para que diese una nueva oportunidad a una paz negociada entre príncipes católicos se convirtió en una auténtica quimera. Los acontecimientos posteriores hubieron de confirmar la incapacidad de la curia romana para frenar la guerra en Europa.

Durante las siguientes semanas la presencia militar hispano-francesa y austriaca a ambos lados de los Alpes se incrementó de forma notoria. El Imperio, a la espera de poder contar con algunos regimientos de caballería y artillería ${ }^{39}$, estableció el grueso de su ejército en el Trentino, mientras que Francia y España situaron sus efectivos fundamentalmente en los ríos Adige y Po. A finales del mes de mayo, las tropas borbónicas del príncipe de Vaudemont y el conde de Tessè desplegadas en ese territorio rondaban las 11.000 unidades $^{40}$. La concentración de fuerzas hispano-francesas en los valles padanos respondía a un doble motivo: estratégico, pues por esta zona discurrían algunas de las más importantes vías de comunicación del norte de Italia; e intimidatorio, como fórmula con la que tratar de aplacar, al menos de forma momentánea, las pretensiones imperiales en la Península. Pero, pese a todo, Leopoldo I no se amedrentó y envió a sus tropas al sur de los Alpes. El 9 de julio el nuncio Cusani informó desde Venecia a la Secretaría de Estado del establecimiento de tres campamentos imperiales en las proximidades de Castelbaldo, una localidad a orillas del Adige, muy cercana a la frontera septentrional de los Estados Pontificios, y de las primeras escaramuzas entre los ejércitos de Francia y el Imperio ${ }^{41}$.

Ese primer frente a frente entre imperiales y borbónicos marcó el definitivo fracaso del proyecto de mediación de la Santa Sede: la guerra, pese a que no se declaró oficialmente hasta 1702, finalmente había llegado a Italia. De nada había servido la neutralidad de Clemente XI. La desolada imagen del pontífice que, poco antes, se había visto en la procesión del Corpus Domini -el jueves 26 de mayo-, con la notoria ausencia de los embajadores en el cortejo a consecuencia de las continuas disputas con el Gobernador de Roma durante todo el XVII, representaba la soledad política del papado a comienzos del nuevo siglo ${ }^{42}$. En algo menos de ocho meses las esperanzas

38. Así lo refiere el nuncio Cusani. Venecia, 7 de mayo de 1701. ASV, Segr. Stato, Venezia, 149, ff. 355356.

39. Cfr. F. VAlesio, Diario di Roma (ed. G. SCANO), Roma, 1977, vol. I, p. 373.

40. Situación más o menos estable desde, al menos, el 14 de mayo de 1701. Cfr. Relazione del campo delle due Corone (anexo a un correo del nuncio Cusani al cardenal Paulucci). Venecia, 27 de mayo de 1701. ASV, Segr: Stato, Venezia, 149, ff. 395-397.

41. Carta del muncio Cuisani al cardenal Paulucci. Ivi, ff. 528-529.

42. M. A. VisCeglia, Tra liturgia e politica: il Corpus Domini a Roma (XV-XVIII secolo), en R. BöseL, G. Klingenstein, A. Koller, Kaiserhof-Papsthof (16-18. Jahrhundert), Viena, 2006, p. 166. 
del nuevo papa y del grupo zelante se habían desvanecido ante el poderío militar de Francia y Austria. Las posteriores alternativas planteadas por Roma para hacer frente al conflicto -alianzas con los estados italianos, envío de nuncios extraordinarios a las cortes de Madrid, Viena y París...- se demostraron insuficientes dado su escaso poder de convicción. Para hacer frente a los imperiales y a sus exigencias, Roma sólo podía confiar en que las continuas levas que había venido haciendo de forma simultánea a las negociaciones por la paz lograsen hacer de sus tropas un ejército compacto, potente y respetado, al menos, en Italia. A principios de marzo de 1701, tras el reclutamiento de 8.000 hombres, el ejército pontificio ascendía a 36.000 unidades, una cifra que no debió de aumentar mucho más en los meses sucesivos ${ }^{43}$. Las cábalas de los astrólogos saludaban al año 1702 con «un preludio infausto di guerre et altre calamità all'Italia» ${ }^{44}$, que Clemente XI no había podido evitar durante su primer año de pontificado.

\section{LA INVESTIDURA DEL REINO DE NÁPOLES COMO INSTRUMENTO DE MEDIACIÓN}

Cuando los representantes de las Dos Coronas en Roma hicieron las primeras instancias al pontífice para la concesión de la investidura de Nápoles, Felipe V y su séquito ni tan siquiera habían tenido tiempo de hacer su ingreso en Madrid y, menos aún, de esbozar los pasos a seguir en la nueva política española. Clemente XI rechazó abiertamente las peticiones del cardenal Janson y del duque de Uceda el 15 de febrero de 1701, tres días antes de que Felipe V llegase a las inmediaciones de la capital de España. La precocidad de los hispano-franceses era evidente si se comparaba con el inmediato antecedente de la coronación de Carlos II. En aquella ocasión la Santa Sede había tardado más de nueve meses en reconocer los derechos del monarca español sobre Nápoles y Sicilia. Sin embargo, su celeridad encontraba justificación: la previsible oposición austriaca a que la Casa de Borbón controlase los territorios españoles en Italia. La negativa del pontífice se cimentaba en bases aparentemente menos sólidas; aunque Clemente XI había reconocido a Felipe V como rey de España el 6 de febrero de aquel año, conscientemente no había querido pronunciarse sobre la concesión de la investidura del reino de Nápoles. El doble juego de la Santa Sede se debía a la coyuntura internacional y a sus deseos de mediación en política exterior. Roma sabía que teóricamente podía acceder a las pretensiones de Francia y España, pero no olvidaba que tal gesto suponía entrar en conflicto con el Imperio, que también había solicitado la titularidad de ese feudo de la Iglesia. Era necesario, decía el pontífice, más tiempo

43. Avvisi Marescotti. Roma, 5 de marzo de 1701. BNCVE, Vitt. Em., 790, f. 92 r; a partir de esa fecha, los avisos de ese año sólo dan cuenta de reclutamientos esporádicos que en ningún caso superan los 300 soldados.

44. F. VALESIO, op. cit, vol. II, p. 13. 
para poder decantarse por una decisión justa y «non precipitare cos'alcuna, perche ciò potrebbe eccitare un maggior fuoco $\rangle^{45}$.

La respuesta de Clemente XI a los representantes de las Dos Coronas ilustra el plan de la Santa Sede con respecto a la utilización política de la investidura de sus feudos durante la Guerra de Sucesión española. La dilación de su concesión tenía que servir para ganar tiempo frente a los deseos del Imperio de iniciar un conflicto bélico de dimensiones continentales. Mediante este gesto de imparcialidad, que seguía la fórmula del secuestro neutral propuesta por Leopoldo I, se pretendía que los ejércitos extranjeros permaneciesen alejados de Italia y reforzar el protagonismo del pontífice en la mediación de un enfrentamiento entre dos príncipes católicos. El planteamiento se concretó poco después con una medida elocuente. El 7 de abril de 1701 Clemente XI designó una congregación especial encargada de estudiar la concesión de la investidura de Nápoles formada por los cardenales Acciaioli, Barberini, Paulucci, Sacripante, Spinola, Ottoboni, Carpegna, Marescotti, Spada, Panciatici, Bichi y Sperelli y otros seis prelados de menor rango ${ }^{46}$. La medida no buscaba realmente llegar a un acuerdo inmediato sobre la titularidad legal del reino sino que más bien tenía por objeto acallar las continuas quejas que monseñor Acquaviva registraba en Madrid por el retraso de la investidura y permitir a la Santa Sede refugiarse en el mutismo. En los días sucesivos, Roma sólo se preocupó, en lo referente a Nápoles, de la provisión de las iglesias de nómina regia mediante el breve de capienda possessione, con la consiguiente negativa del gobierno español ${ }^{47}$. La estrategia pontificia había servido para ganar algo de tiempo pero no demasiado. El 5 de mayo Paulucci dio órdenes al nuncio en Madrid para que hiciese saber en esa corte que si Clemente XI, pese a conocer las razones de Felipe V para ocupar el trono partenopeo, todavía no había tomado una decisión, se debía a que permanecía a la espera de que el embajador Lambergh presentase las justificaciones del Imperio sobre esa misma materia ${ }^{48}$. Tan sólo diez días después se escribió de nuevo al nuncio ratificando la voluntad del pontífice de analizar en profundidad el problema de la investidura. En la epístola se explicaba con tono paternal que si la congregación especial convocada por el papa a tal propósito sólo se había reunido una vez hasta la fecha, no debía interpretarse como fruto del desinterés de la curia romana por ese tema,

45. Así se decía en la Risposta di Clemente Undecimo Pontefice, alli rappresentanti di Filippo Quinto Rè di Spagna e di Luigi XIIII di Francia e mottivi per li quali non accorda a detto Filippo Quinto Rè di Spagna I'Investitura di Napoli, che richiede (copia). Roma, 15 de febrero de 170l. ASV, Fondo Bolognetti, 129, ff. 302-303.

46. La fecha exacta se recoge en el diario de F. VALESIO, op. cit., vol. I, p. 341; la lista de los miembros de la congregación en Despacho del embajador veneciano en Roma Niccolò Erizzo. 9 de abril de 1701, F. NICOLINI, L'Europa durante la guerra di successione di Spagna vol. II, pp. 115-116, y también en F. POMETTI, Studi sul pontificato di Clemente XI (1700-1721), «Archivio della Regia Societa Romana di Storia Patria», XXI, 1898, p. 322.

47. Cfr. ASV, Segr. Stato, Spagna, 183, ff. 268-271.

48. Cfr. Carta del cardenal Paulucci al nuncio Acquaviva. Roma, 5 de mayo de 1701. ASV, Arch. Nunz Madrid (Archivio della Nunziatura di Madrid), 47, ff. 121 y ss. 
sino como la prueba de que era un asunto que requería de la reflexión. Clemente XI se maravillaba, con una prepotencia poco acorde con la realidad,

«di vedere tanta insistenza che le pare non meritarla da cotesta parte; mentre la Santità Sua non hà sin ora dichiarata alcuna Intenzione contraria, ò fatta dimostrazione positiva, che privi Sua Maestà del possesso del Regno di Napoli; anzi lascia, che vi tenga i suoi ministri, e Sua Beatitudine medesima, vi tiene pregio senza verun'alterazione ò cambiamento di cose dal canto suo».

Dadas las importantes causas de la dilación, se esperaba que sólo con leer esas razones en la corte de Madrid fuese suficiente para convencer a Felipe V y a sus ministros de la necesidad de disponer de más tiempo para el asunto de la investidura ${ }^{49}$. Quizás era una presunción excesiva. La excepcionalidad del momento, con dos poderes que pugnaban por la titularidad reconocida de un mismo reino, no ayudaba precisamente a guardar la calma y a permanecer a la expectativa.

Según se acercaba la festividad de los Santos Pedro y Pablo -el 29 de junio-, aumentaba el nerviosismo en el seno de la curia romana. Se temía que la víspera de ese día, momento en el que tradicionalmente tenía lugar la ceremonia de la chinea, con la que se solemnizaba la concesión de la investidura del reino de Nápoles, se registrasen disturbios provocados por españoles e imperiales. Ese fue el motivo que llevó a Clemente XI a hacer público un documento en el que hacía saber que el pago de los 7.000 escudos y la presentación de la hacanea, que tradicionalmente solía hacer un representante del Rey Católico, quedaban en suspenso hasta nuevo aviso; se recalcaba además, para no dejar lugar a posibles dudas, que la «dilazione, e non pagamento e presentazione della Chinea in detta festa» no perjudicaban a los derechos de la Santa Sede sobre su feudo ${ }^{50}$.

Los temores de Clemente XI no eran infundados. El duque de Uceda se movía dentro de unos difíciles parámetros de acción -definidos vagamente desde Madridque, dependiendo de las decisiones del pontífice sobre Nápoles, podían complicar el normal discurrir de los últimos días de aquel mes de junio romano; tras debatir con algunos de sus hombres el modo de actuar, dispuso una estrategia que rozaba lo burlesco ${ }^{5 !}$. El día 28 el agente español Alonso Torralba se las ingenió para introducir a un malherido caballo blanco, que tiraba de un carro cargado de verduras, en el patio de la Cámara Apostólica. Dejados atrás los guardias suizos, que tenían órdenes de controlar movimientos sospechosos de los españoles, Torralba, con una cédula en mano por valor de 7.000 escudos, comenzó a enumerar cada uno de los feudos del reino de

49. Cfr. De la Secretaria de Estado al nuncio Acquaviva. Roma, 15 de mayo de 1701. ASV, Fondo Albani, 55 , ff. 137-139.

50. Chirografo di Clemente XI. Roma, 26 de junio de 1701. ASV, Arch. Nunz. Madrid, 48, f. 23.

51. Cfr. M. A. OCHOA BRUM, Embajadas rivales: la presencia diplomática de Espana en Italia durante la Guerra de Sucesión, p. 26. Indicaré además, entre las abundantísimas relaciones de la estratagema, las descritas por F. M. OTTIERI, Istoria delle guerre avvenute in Europa e particularmente in Italia paer Ia successione alla monarchia delle Spagne dall'anno 1696 all'anno 1725, t. H., Roma, 1752, pp 191-192; y F. VALESIO, op. cit., vol. I, p. 412. 
Nápoles, mientras mandaba a los miembros de su séquito descubrir la gualdrapa con las armas pontificias que llevaba el caballo. El acto, pese a entrar dentro de la legalidad en sus parámetros formales, provocó el rechazo general de la curia. Los funcionarios pontificios no aceptaron el donativo e ignoraron la presencia del animal en las dependencias pontificias. Sólo a la una de la madrugada los guardias suizos se decidieron a expulsar al pobre caballo. Antes, la embajada de España había hecho pública una protesta por el rechazo de la hacanea en la supuesta ceremonia de la investidura. La rocambolesca presentación se justificaba como la medida adecuada para evitar «que en ningun tiempo pudiesse resultar perjuicio à Su Magestad Catholica, ni se pudiesse tomar motivo para alegar haver faltado a la continuacion de la mayor reverencia, y obsequio à la Santa Sede» ${ }^{52}$.

El episodio, gracias a una comicidad digna de la mejor comedia barroca, pronto alcanzó gran difusión en Europa y fue utilizado para desacreditar el respeto de los españoles hacia la Santa Sede. Las críticas tenían buena parte de razón: la ceremonia civil más importante del calendario romano $0^{53}$ había sido puesta en ridículo por la embajada de España y no volvería a celebrarse hasta la subida de Carlos de Borbón al trono del Reino de las Dos Sicilias. Pero no fue ésa la consecuencia más importante que trajo consigo la supuesta presentación. Hispano-franceses e imperiales quedaron enfrentados definitivamente en (y por causa de) Roma por la titularidad del reino de Nápoles y el proyecto pontificio de hacer de ese feudo un símbolo de neutralidad se convirtió, para Austrias y Borbones, en causa de recíprocas sospechas de parcialidad. Por un lado, Lambergh temía que Clemente XI reconociese los derechos de Anjou para evitar una ruptura de relaciones con Madrid; por otro, Uceda creía que el papa había pactado con el emperador para no conceder la investidura de Nápoles hasta que no terminase la guerra, que formalmente todavía no había comenzado ${ }^{54}$.

Pero era evidente que, tras el rechazo, la Santa Sede iba a encontrar mayor oposición por parte de los españoles. En la corte madrileña los retrasos en la concesión del feudo napolitano venían siendo desde hace tiempo motivo de intranquilidad y ya a comienzos de verano se comenzaban a asociar con la denegación $n^{55}$. Cuando llegaron las primeras noticias del episodio de la chinea (planeado secretamente en una reunión en la que participaron el duque de Uceda, los cardenales Giudice y Janson, monseñor Molines y el agente Alonso de Torralba) a Madrid, los ministros de Felipe V, pese a reconocer la poca ortodoxia en el proceder de los representantes españoles ante la Santa Sede, decidieron felicitarles abiertamente por no haber acatado las disposiciones

52. Protesta Otorgada sobre la Presentacion de la Accanea en 28 de Junio de 1701. BEESS (Biblioteca de la Embajada de España ante la Santa Sede), 205, ff. 171-178.

53. M. GORI SASSOL, La città della rappresetazione le feste e gli spetiacoli, en G. CuCCI, Roma Moderna, Roma-Bari, 2002, p. 189.

54. Cfr. M. A. OCHOA BRUM, op. cit., pp. 25-26.

55. Carta del muncio Acquaviva al cardenal Paulucci. Madrid, 7 de julio de $1701^{-}$. ASV, Segr Stato, Spagna, 183, ff. 440-441. 
pontificias sobre la suspensión de la ceremonia de la hacanea ${ }^{56}$. El gobierno de España no sólo no pensaba condenar a sus agentes sino que estaba dispuesto a reconocer su servicio a la Corona. Los derechos históricos de la Santa Sede sobre el reino de Nápoles habían dejado de ser un referente de la neutralidad pontificia en el conflicto sucesorio y ahora corrían el riesgo de convertirse en una amenaza para el proyecto de mediación. A comienzos del otoño de aquel año se produjo un acontecimiento que dejó entrever que la investidura del feudo no iba a depender tanto de la voluntad de la curia romana -sobre la que aumentaban las acusaciones de imparcialidad- como del poderío militar de los candidatos que se batían por él.

La noche del 24 de septiembre de 1701, al grito de «Viva l'imperadore e fuor gabelles ${ }^{57}$, estalló en Nápoles una revuelta contra el gobierno borbónico del reino. EI virrey Medinaceli y su séquito se vieron obligados a refugiarse en uno de los castillos de la ciudad por la presión de los rebeldes -entre los que se contaban cerca de sesenta caballeros-, pero la conocida como Conjura del príncipe de Macchia no obtuvo el apoyo deseado entre la nobleza local y no tardó en ser sofocada y reprimida con dureza por los españoles ${ }^{58}$. Se descubrió muy pronto que la operación se había gestado en una serie de encuentros en Roma de algunos nobles napolitanos con el conde de Chassignet, un agente austriaco enviado a Italia poco antes por el emperador ${ }^{59}$, y que en ella estaban implicados numerosos eclesiásticos. La proximidad de los Estados Pontificios y el reino de Nápoles y las múltiples relaciones de ambos territorios facilitaban considerablemente este tipo de prácticas. Cuando en la curia romana se tuvo conocimiento del tumulto, Clemente XI se apresuró a enviar instrucciones al arzobispo Cantelmi para que castigase con penas espirituales y temporales a aquellos prelados acusados de sediciosos y que hiciese difundir entre el pueblo que la Santa Sede, pese a no haber concedido aun la titularidad del reino, no dudaba de los derechos de la Casa de Borbón. Desde hacía algunos meses se detectaba en Roma excesiva libertad en las críticas hacia la administración borbónica en Nápoles y había quien creía que el papa tenía motivos más que suficientes para intentar frenar el peligro: «con la sua pertinacia nel negare l'investitura a Filippo $V$, aveva dato, sia pure senza volerlo, una forte spinta al moto rivoluzionario, che, riuscendo, avrebbe travolto senz'altro lo Stato pontificio nella guerra $\rangle^{60}$.

56. Carta del nuncio Acquaviva al cardenal Paulucci. Madrid, 8 de agosto de 1701. Ivi, f. 530.

57. Según un cronista anónimo de principios del siglo XVIII. Cfr. DE BLASIIS, G., Diario napoletano dal 1700 al 1709, «Archivio storico per le province napoletane», X, 1885, pp. 85-129.

58. Véase el estudio clásico de A. GraniTo, Storia della congiura del principe di Macchia, Nápoles, 1861.

59. in0 Puede consultarse una copia de las instrucciones secretas del emperador al conde que se conserva en ASV, Fondo Bolognetti, 129, ff. 304-314. Chassignet tenía órdenes de apoyar a Giuseppe Capece y al resto de los conjurados para mantener y promover el apoyo a la causa imperial en diversos sectores napolitanos.

60. Despacho del embajador veneciano en Roma Niccolò Erizzo. 27 de septiembre de 1701, en F. NICOLINl, op. cit., vol. III, p. 227 


\section{APUNTES SOBRE EL FRACASO DE LA MEDIACIÓN}

La principal pretensión del proyecto político que guió los comienzos del pontificado de Clemente XI fue hacer de Roma un referente en las relaciones internacionales. Sin embargo, muy pronto quedó patente que las ambiciosas expectativas del pontífice no correspondían con la realidad. ¿Por qué se desplomó la política exterior de la Santa Sede al inicio de la Guerra de Sucesión española? Aparentemente podría decirse que el fracaso pontificio radicó precisamente en que la curia romana no fue capaz de evitar el estallido de la contienda. En realidad, la respuesta a esa pregunta está más relacionada con la actitud del pontífice y del grupo zelante ante la situación política de la Europa de su tiempo y el modo de posicionarse en ella que con la imposibilidad de evitar la entrada de las tropas imperiales en Italia. Se trata, en el fondo, de una cuestión de premisas: Clemente XI quiso seguir mediando entre el duque de Anjou y el archiduque Carlos cuando para casi toda Europa (y también para él), desde que se hizo público el testamento de Carlos II, se trataba de un enfrentamiento entre el legítimo rey de España y un nieto del emperador. El pontífice, animado por el carácter universal de la soberanía espiritual ostentada por la Santa Sede, pretendía ser neutral con esa posición ${ }^{61}$. En el razonamiento pervivía inalterable el viejo dualismo de la figura del Papa-Rey ${ }^{62}$.

El planteamiento llevó a Clemente XI a utilizar sus derechos sobre Nápoles y Sicilia como prueba de neutralidad. El pontífice pensó que el retraso de la investidura del reino facilitaría que Austrias y Borbones viesen en la Santa Sede un mediador válido e imparcial y que el diálogo acabaría con las amenazas de guerra que se cernían sobre Italia. Nápoles era la pieza clave del proyecto pontificio. Se creía que gracias a él, Roma podría recuperar su centralidad en la política europea (se situaba justo en medio de las disputas de Francia y España con el Imperio) y mantener la paz en los Estados Pontificios y el resto de la Península. Las ideas sobre el sur de Italia que se habían forjado en la curia romana muy pronto se demostraron equivocadas. La dilación en la concesión del feudo a Felipe V sólo sirvió para interferir en el dominio efectivo de los españoles y para que aumentase la inestabilidad. La Conjura del principe de Macchia fue el ejemplo más esclarecedor de las trabas que la Santa Sede, inconscientemente, estaba poniendo a la tranquilidad al sur de los Alpes.

En diciembre de 1700 el virrey Medinaceli había esbozado una de las claves para el mantenimiento de la paz: la formación de una coalición de estados italianos que fuese capaz de obligar al emperador a desistir en su empeño bélico. La propuesta, lejos de ser el resultado de una estratagema de un súbdito de Felipe V para ganarse el favor de los príncipes de la Península, estaba formulada en términos tremendamente objetivos. «Non parlo da ministro spagnuolo -llegó a decir Medinaceli al residente veneciano en Nápoles-, ma da buon italiano, giacchè, avendo trascorso nella penisola

61. F. POMETTI, op. cit., XXI, p. 313.

62. Sobre el origen y rasgos de esta figura véase el célebre estudio de P. PRODI, Il sovrano pontefice, Bolonia, 1982. 
diciassette anni della mia carriera, amo l'Italia e vorrei che si difendesse da sè̀ ${ }^{63}$. La sinceridad de su propuesta derivaba de sus reticencias a que las tropas de Luis XIV atravesasen los Alpes. Temeroso, como era, de que los franceses se estableciesen perennemente en Milán y que, cuando ya no hubiese necesidad de su apoyo militar, se negasen a abandonar esa plaza, confiaba en la consolidación de una liga italiana para que Felipe $V$ no tuviese que pedir socorros a su abuelo.

La red de hermandad que trató de tejer Medinaceli, y que más adelante hubo de retomar D’Estrées, en nombre de Francia, no tuvo éxito. Por más que perseveró en su intento, representando los males que traería para los Estados Pontificios y para sus habitantes una guerra en Italia, de la Santa Sede no halló más que el ciego empecinamiento del pontífice en mantenerse neutral; de Venecia, un mutismo que hacía de la República un espectador privilegiado del conflicto. El difícil momento que atravesaban las relaciones entre el Senado y la Curia, con la controvertida embajada de Erizzo, tampoco ayudaba al virrey y a su proyecto; al menos por lo que a la Santa Sede se refiere, quedó prácticamente relegado al olvido. Sólo cuando la presión austriaca en las tierras del norte de Italia se hizo insoportable, Clemente XI retomó con discrección el plan de Medinaceli. Las instrucciones de la Secretaría de Estado al nuncio Cusani en caso de propuesta de coalición de Venecia o, incluso, de Francia resultan esclarecedoras: «lei ascolti, riferisca a noi, e non risponda. Dirà soltanto di sapere che la medesima Sua Santità ha avuto sempre et ha quei sentimenti, che nelle correnti particolari emergenze convengono alla sua obligazione ${ }^{64}$. Sin embargo, el tentativo de construir un eje Roma-Venecia, al que habrían de unirse, casi por inercia, el resto de estados italianos, llegaba demasiado tarde. Cuando la Santa Sede comenzó a considerar la opción, Saboya ya había jurado fidelidad (efímera) a las Dos Coronas y la desconfianza hacia los venecianos, de los que se creía que serían capaces de permitir al Imperio el paso de sus tropas por los territorios de la República, era muy alta. La situación política de la Península a mediados del año 1701 hacía imposible que la liga pudiese llegar a materializarse.

No había sido ésa la opción preferida por la Santa Sede. Clemente XI había apostado desde su elección por la mediación, y lo había hecho por una doble motivación: la promoción de la imagen de la Santa Sede en el panorama internacional y el mantenimiento de la paz, al menos en Italia. La evolución de los primeros años de su pontificado demuestra que esas dos aspiraciones eran incompatibles. Si Clemente XI hubiese ratificado los derechos de la Monarquia española sobre el reino de Nápoles y hubiese accedido inmediatamente a aliarse con el resto de estados italianos para intimidar al emperador, su partidismo habría hecho muy difícil cualquier intento de media-

63. Despacho del residente veneciano en Nápoles Savioni. 27 de diciembre de 1701, en F. NICOLIN1, op. cit., vol. II, p. 260; citado también por G. GALASSO, Napoli nel viceregno spagnolo dal 1697 al 1707, en Sioria di Napoli, vol Vli, Nápoles, 1971-72p. 175. También el nuncio en Nápoles, monseñor Casoni, dio cuenta de los planes del virrey al cardenat Paulucci. Cfr. Nápoles, 28 de diciembre de 1700. ASV, Segr. Stato, Napoli, 129, f. 7.

64. F. POMETTi, op. cit, XXI, p. 343. 
ción. Aunque el pontífice, en busca de una mejor sintonía con Austrias y Borbones, se decantó por el arbitraje imparcial entre el archiduque Carlos y Felipe V no obtuvo mejores resultados; sólo consiguió la enemistad de los dos, al negarse a reconocer al primero como rey de España (aunque ya en 1703) y no conceder al segundo la investidura de Nápoles. Pese a que ámbas eran vías que no daban salida a la mediación, la que tomó Clemente XI condujo a un escenario doloroso: un campo de batalla que abarcaba toda la península Itálica.

Quizás si el pontífice hubiese desistido en su empeño por ensalzarse como mediador espiritual y temporal entre príncipes cristianos y hubiese concentrado sus esfuerzos en mantener la paz mediante fórmulas más pragmáticas, hubiese logrado, al menos, mantener la guerra lejos de Italia. La realidad fue muy distinta y el resultado de esta hipótesis jamás podrá ser conocido. Es baladí elucubrar. 